\title{
电梯制动器电气控制及检验探析
}

\author{
秦彦昌 \\ 西继迅达(许昌)电梯有限公司 \\ DOI:10.18686/bd.v2i9.1640
}

[摘要] 随着我国科学技术不断发展, 城市中的高层建筑越来越多, 电梯作为高层建筑中的必备公共设施, 对人们的生活质 量有着直接影响。在电梯安全检测过程中, 电梯电气控制系统安全检验问题受到人们广泛关注。电梯制动电气系统对于电梯 制动安全性有着直接影响。电梯制动器是在电梯出现特殊状况情况下, 完成对电梯的制动, 保障轿厢内人员的安全。而具体 的电梯制动器电气控制及检验问题, 是影响制动器功能发挥的基础, 如不能有效控制, 可能引起电梯制动器失灵问题出现, 导 致隐患发生。基于此, 本文重点探究电梯制动器电气系统检验中的问题,进而提出相应的解决措施。

[关键词] 电梯制动器; 电气控制; 检验

随着电梯安全问题逐渐走人大众视野, 我们对电梯的 工作原理的了解也逐渐深人。众所周知,要使电梯安全运行 无事故,保护使用者的人身财产安全,必须确保电梯的有效 制动。无论是电梯正常运行中在每个楼层的停顿, 还是一旦 出现故障无法正常在楼层停止时, 发挥作用紧急制停下坠 的电梯, 电梯制动器都是最关键的部位。一旦电梯制动器出 现故障, 电梯将无法制停, 极可能出现电梯轿厢从高处芏落 的事故。所以电梯企业必须重视电梯制动器的研发力度, 增 强其安全性和可靠性。

\section{1 电梯制动器电气控制原理}

电梯制动器对电梯而言, 可以被视为电梯的刹车系统, 而电气控制则是控制刹车发动的基础。其中,电梯制动器是 由制动臂、电磁铁和制动弹簧等构件构成, 电梯正常运行状 态,制动器功能不会体现。当电梯正常运行状况时, 制动器会 工作, 电磁制动器的电磁线圈内会存在电流, 会引起制动臂 克服弹簧的压力, 带动制动瓦脱离制动轮, 此时制动器为松 闸状态。一旦电梯发生异常状态, 出现断电或电气安全装置 动作, 则线圈内电流消失,制动臂不能克服弹簧的压力, 制动 瓦接触制动轮, 此时制动器为抱闸状态, 完成对电梯的制动。

\section{2 电梯制动器电气控制系统中存在的问题}

\section{1 制动线路问题}

在电梯运行过程中, 由于电梯制动器中存在安全隐患 从而造成安全事故非常多。制动线路作为制动系统中的硬 件设施, 与电梯的安全性有着直接关联。例如控制系统中两 个接触电路出现粘连问题, 如果电梯在运行过程中出现该 现象, 监控系统与制动反馈系统没有做出反应, 虽然轿厢依 然能够上下运行, 但运行中存在着非常大的安全隐患。再者, 在控制回路过程中, 控制系统中的两个接触器其中一个触 电处于吸合状态, 这时会造成电梯制动器电气控制系统失 效,很容易造成安全事故。

\section{2 制动器电气控制检验问题}

根据相关规定, 制动器需要配置两个独立的电气装置。 且需要在控制线圈电路中设置两个独立的接触器, 并运用
主电源的辅助。还需要设计抱闸接触器, 保障抱闸质量。回 路中,需设计接触器防粘连保护。

2.2.1 电梯制动器电气控制线路检验问题: (1) 接触器触 点出现粘连问题, 倘若系统未能完成对这类现象的警报, 会 引起制动失效的情况, 导致隐患。(2)两个接触器触点, 某一个 处于接触状态、另一个处于吸附状态, 可能会引起电梯出现 冲顶与溜车的情况,引发安全隐患。

2.2.2 电梯制动器电气控制检验问题: (1)控制回路不能 满足接触器独立工作需求, 无法完成对独立信号的控制, 导 致隐患。(2)制动器回路触点仅一个满足监视和回馈要求, 另 一个功能受限, 引起轿厢运行出现上下两个方向运行的情 况。(3)高速运行与低速运行,指标测试结果差異显著。

\section{3 提高电梯制动器电气控制分析及研究的措施}

3.1 对合格信息进行审核

在电梯生产完成之后, 厂家都会对电梯的质量进行检 测, 并对合格的电梯颁发相应的合格证书。在对电梯制动器 电气控制进行分析和检测的时候, 要对电梯电气控制的原 理图进行科学的检测, 将电气原理图和电梯元件进行对比 分析, 看看元件是否是根据原理图生产设计的。另外,也要加 强对电梯内部的构建进行检测, 看看电梯制动器是不是两 个单独的接触器对电梯进行控制, 对线路设计也要仔细的 检测, 要保证线路设计之间的完整性, 确保电梯的顺利运行。

3.2 确保电气装置工作的独立性

电气装置数量符合要求后, 还应该确保其独立性要求。 已知两个电气装置必须由两个独立信号控制, 这是由于如 果两个信号相同, 可能会出现制动器电源切断但是电气装 置启动, 制动器又开启的情况, 因而我们必须研究制动器线 圈的控制线路, 确定两个电气装置的信号来源的独立性。除 此之外, 确保电气装置的独立性, 可以确保另一个电气装置 的触点不影响另外一个电气装置控制的线圈。

3.3 提高质量管理意识

在促进企业快速平稳发展的基础上, 要充分认识到加 强产品的质量管理对企业发展的重要作用, 因此, 要加强企 
业领导层的建设,增加管理的内容,并不断加大管理力度,为 加强产品质量监督管理, 建立一个独立的检查部门,对各部 门的工作进行不定时的抽查。另外, 要加大监察力度,提高产 品质量的管理水平, 建立健全一套监督考查机制, 设定科学 合理的检查标准, 对产品的质量进行定时定量的严格考查, 通过不断地完善质量监督管理体制，提高电梯制动器电气 控制的分析和检查工作。

3.4 对电梯控制器进行模拟实验

在电梯生产完成之后, 进行模拟实验是一个非常重要 的过程, 在进行模拟实验时, 要确保电梯是向着同一个方向 运转的, 另外, 在进行试验的过程中, 要按住电梯控制器的主 要控制点,观察电梯向着反方向是否运转,如果电梯没有朝 着反方向运转, 那就说明电梯控制器电气控制是符合生产 使用要求的, 如果电梯向反方向运转或者出现滑梯的现象, 就说明电梯制动器的电气控制不符合生产要求, 应进行及 时的调整。

\section{4 电梯制动器出厂检验及型式实验项目和方法}

4.1 电梯制动力矩的实验

需要根据计算数据在实验台上测定制动能力, 实验时 需要确认引擎的状态,并且在仔细查看后, 轮轴上的扭矩则 不会出现打滑的情况。增加扭矩后用夹具将杜杆固定至机 轴之上, 在此处可用弹簧测力计自由的垂直于拉杜杆, 这样 就是一种非动态的制动扭矩, 其拉力的大小与距离值相乘 即可。

4.2 电梯制动器的电磁铁实验

必须让使用经过检查合格的变压器、电压表, 测试电梯 制动器线圈产生最小工作电压。这时就可用电子计时器、通 用秒表进行测量, 这样可知道制动器开启以及滞后所花费 的时间。

4.3 电梯制动器线圈的抗压力实验

可使用耐压的测试仪渐渐提升电压的强度, 以测试线 圈导电体对地面的绝缘的强度。

4.4 电梯制动器的运行实验

需要先使电机处在静止的状态下, 把电梯制动器装在 引擎之上,之后可开展更多的实验,并且在实验过程中, 不可 维护任何的部件, 当实验完后, 再将所要达到的规定要求提 出即可。

5 电梯制动器安装监督检验以及定期检验的有关方法

根据国家法律法规的规定, 不管是电梯的安装还是改 造、重大维修等过程都需要检验、检测机构开展监督检验,
检验不合格者不可出厂、交付使用。同时还规定使用单位一 定要每一个月对其开展自行安排检查,记录有关数据,并且 必须在合格有效期届满前一个月向检验检测的机构, 提出 定期检验的有关需求，未经定期检验或是检验不合格的不 可以继续进行使用。从这里我们可以看出,合格制动器在电 梯安装、维修时都要有监督检验。在有效使用期间要自行定 期检查,且可在合格有效期满时,要求有关部门开展定期检 验。

5.1 电梯制动器机械部件设置, 根据电梯监督检验规则 需要提供相关报告, 对照实际情况查明各机械部件设置哪 些受制动的装置等,还要再进行更多的实验。

5.2 电梯制动器电气装置设置, 我们可根据电梯监督检 验规则、电气工作原理图以及实际情况, 在工作机房对电梯 制动器电气装置开展系列模拟实验。当电梯启动工作程序 后还要及时根据接触器工作主触点, 位于电梯制动器电磁 感应线圈电气装置中。等电梯运行直至停止后可放开主触 点。

5.3 电梯紧急手动操作方式。需通过手动松开并且操作 松闸装置中电梯制动器, 可验证是否有必要松开这样的状 态。

5.4 电梯上行制动的实验, 电梯轿厢空载, 可以正常运行 速度上升到顶层上端部时, 这时可断开主开关,检查电梯轿 厢制停的情况,以及轿厢的变形损坏的实际情况。

\section{6 结语}

随着电梯发生的安全事件越来越多, 电梯运行安全是 人们高度重视的课题。而电梯制动器是控制电梯运行安全 的重要元件,做好是其电气控制及检验非常重要。因此就需 要从检验现在中分析存在的问题, 电气装置数量符合要求 后,还应该确保其独立性要求; 加强企业领导层的建设,增加 管理的内容,并不断加大管理力度,提高电梯制动器电气控 制的分析和检查工作。

\section{[参考文献]}

[1]雷玉君.电梯制动器电气控制及检验方法探析 [J]. 中国新技术新产品,2017(08):54-55.

[2]曾相红. 关于电梯制动器的电气控制分析[J]. 科技 展望,2017(5):100.

[3]张云峰, 郑翰晖. 电梯制动器电气控制及检验问题探 讨[J]. 电子世界,2014(06):276.

[4]华影.电梯制动器电气控制及检验问题探析 [J]. 中 国设备工程,2016(07):52+55. 